\title{
Idiopathic scoliosis in children and adolescents: assessment with a biplanar X-ray device
}

\author{
Elisa Amzallag-Bellenger • Fabian Uyttenhove • Éric Nectoux • \\ Antoine Moraux • Julien Bigot $\cdot$ Bernard Herbaux $•$ Nathalie Boutry
}

Received: 2 May 2014 / Revised: 20 August 2014 / Accepted: 26 August 2014 /Published online: 13 September 2014

(C) The Author(s) 2014. This article is published with open access at Springerlink.com

\begin{abstract}
Idiopathic scoliosis is one of the most common conditions encountered in paediatric practice. It is a three-dimensional (3D) spinal deformity. Conventional radiography is still the modality of choice for evaluation of children and adolescents with idiopathic scoliosis, but it requires repeat radiographs until skeletal maturity is reached and does not provide information about spinal deformity in all three planes. A biplanar $\mathrm{X}$-ray device is a new technique that enables standing frontal and lateral radiographs of the spine to be obtained at lowered radiation doses. With its specific software, this novel vertical biplanar X-ray unit provides 3D images of the spine and offers the opportunity of visualising the spinal deformity in all three planes. This pictorial review presents our experience with this new imaging system in children and adolescents with idiopathic scoliosis.
\end{abstract}

\section{Key Points}

- The biplanar X-ray device produces two orthogonal spine Xray images in a standing position.

- The biplanar X-ray device can assess idiopathic scoliosis with a lower radiation dose.

- The biplanar X-ray device provides $3 D$ images of the spine.

E. Amzallag-Bellenger $\cdot$ F. Uyttenhove $\cdot$ A. Moraux $\cdot$ J. Bigot $\cdot$

N. Boutry

Department of Paediatric Radiology, Jeanne de Flandre Hospital,

Lille 2 University, University Hospital of Lille, Lille, France

É. Nectoux $\cdot$ B. Herbaux

Department of Paediatric Orthopaedics, Jeanne de Flandre Hospital, Lille 2 University, University Hospital of Lille, Lille, France

N. Boutry $(\square)$

Service de Radiopédiatrie, Hôpital Jeanne de Flandre, Avenue Eugène Avinée, CHRU de Lille, 59037 Lille, France e-mail: nboutry@gmail.com

N. Boutry

e-mail: nathalie.boutry@chru-lille.fr
Keywords Idiopathic scoliosis · Radiography $\cdot$ Low-dose digital imaging system $\cdot 3 \mathrm{D}$ reconstruction

\section{Introduction}

Scoliosis is defined on radiographs by the presence of one or more lateral curvatures of the spine in the coronal plane, greater than $10^{\circ}$ as measured by the Cobb method [1]. There are no identifiable causes for this condition in about $80 \%$ of cases and, in particular, no evidence of congenital, developmental or neuromuscular abnormalities [1]. On the basis of patient's age and clinical features, idiopathic scoliosis is categorised as infantile ( $0-3$ years) scoliosis (male predominance, levoscoliosis more frequent), juvenile (4-10 years) scoliosis (female predominance, dextroscoliosis more frequent) and adolescent (11-18 years) scoliosis (female predominance, dextroscoliosis more frequent) [1].

Radiography is the mainstay to confirm the diagnosis of idiopathic scoliosis in excluding underlying causes (e.g. segmentation abnormalities), to characterise the type of spinal curvature(s), determine the flexibility of the curvature(s), follow disease progression and monitor treatment. Standard evaluation consists of standing frontal radiographs of the entire spine (either anteroposterior [AP] views in males or posteroanterior [PA] views in females in order to reduce the radiation dose to the breasts), sometimes completed by lateral radiographs. However, radiography has two main disadvantages. Firstly, repeated examinations (it is estimated that a typical scoliosis patient will have approximately 22 radiological examinations over a 3-year treatment period [2]) are responsible for an increased amount of radiation exposure and, particularly in young females, an increased risk of breast cancer or infertility [2-5]. Secondly, scoliosis corresponds in reality to a complex three-dimensional (3D) deformity of the spine that simple two-dimensional (2D) radiographs are unable to assess precisely. 
Fig. 1 Imaging technique of the EOS 2D system. The gantry is composed of two sets of X-ray tubes and detectors positioned orthogonally and supported by a mobile arm. This arm moves vertically while the patient is positioned upright at the intersection of the two X-ray fanbeams. A single scan can produce both $\mathrm{AP}$ and lateral radiographs of the spine, the lower limbs or the whole skeleton

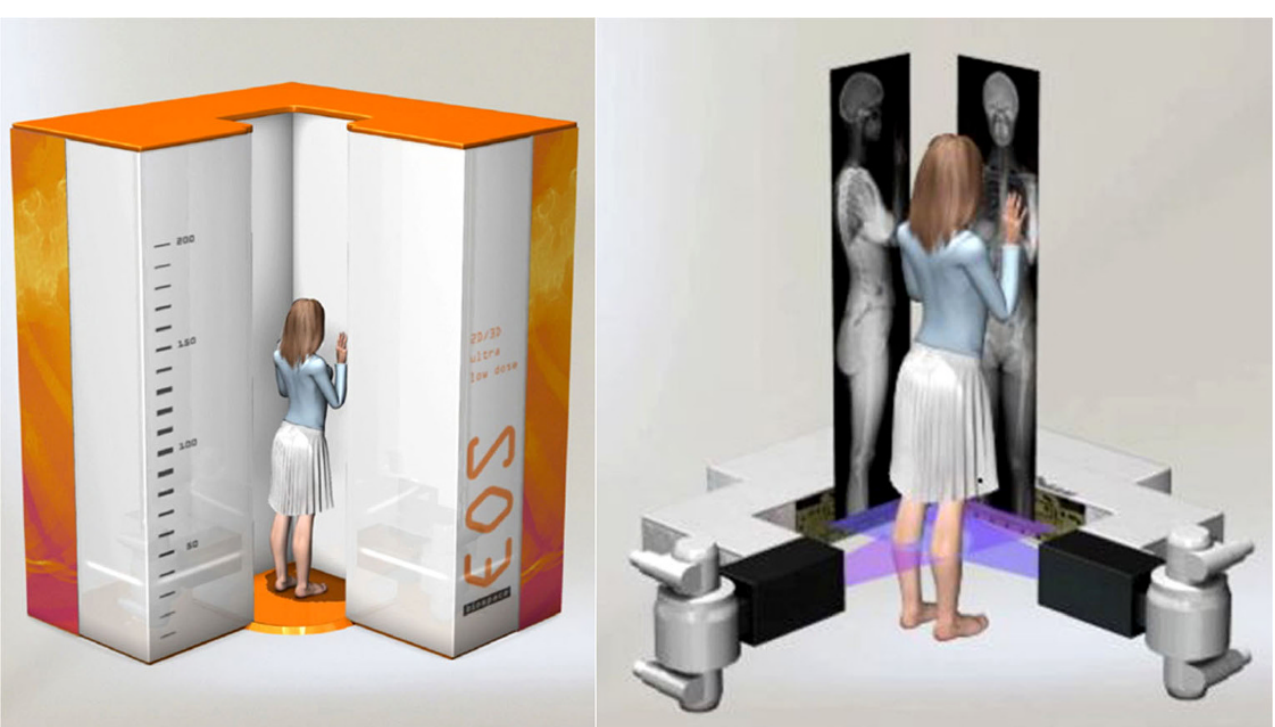

During the past decade, a new imaging technique based on George Charpak's gaseous particle detector technology
(Nobel Prize in Physics, 1992) has developed in order to solve these issues [6]. Also known as the EOS imaging system
Fig. 2 Radiographs of the spine and lower limbs in a 7-year-old boy. AP and lateral images are simultaneously obtained (a), allowing for surface 3D reconstructions (b). Relationships between the spine and the lower limbs can be assessed. [Total cumulative $\left.\mathrm{DAP}=584 \mathrm{mGy} \cdot \mathrm{cm}^{2}\right]$
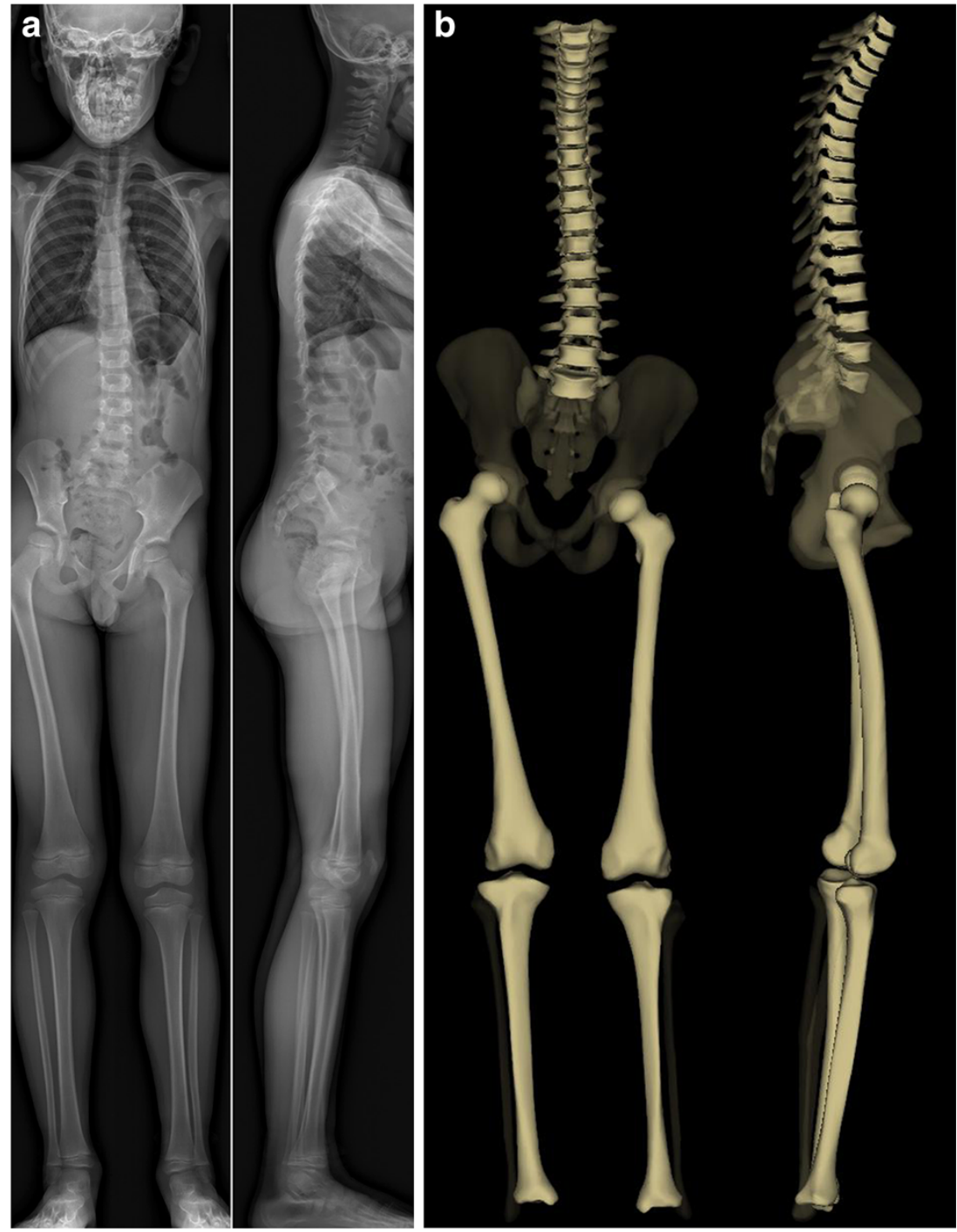
Fig. 3 Motion artefacts with the EOS 2D system. Lateral views of the lumbar spine in a 7-year-old boy suffering from an anterior spondylolisthesis of L5 related to a pars interarticularis defect are shown. Child's movement during the image acquisition (on the left) is responsible for a distorted aspect of the spine and the proximal femurs (arrows). Compare with another lateral view in the same patient without artefacts (on the right). [Total $\mathrm{DAP}=140 \mathrm{mGy} \cdot \mathrm{cm}^{2}$ ]

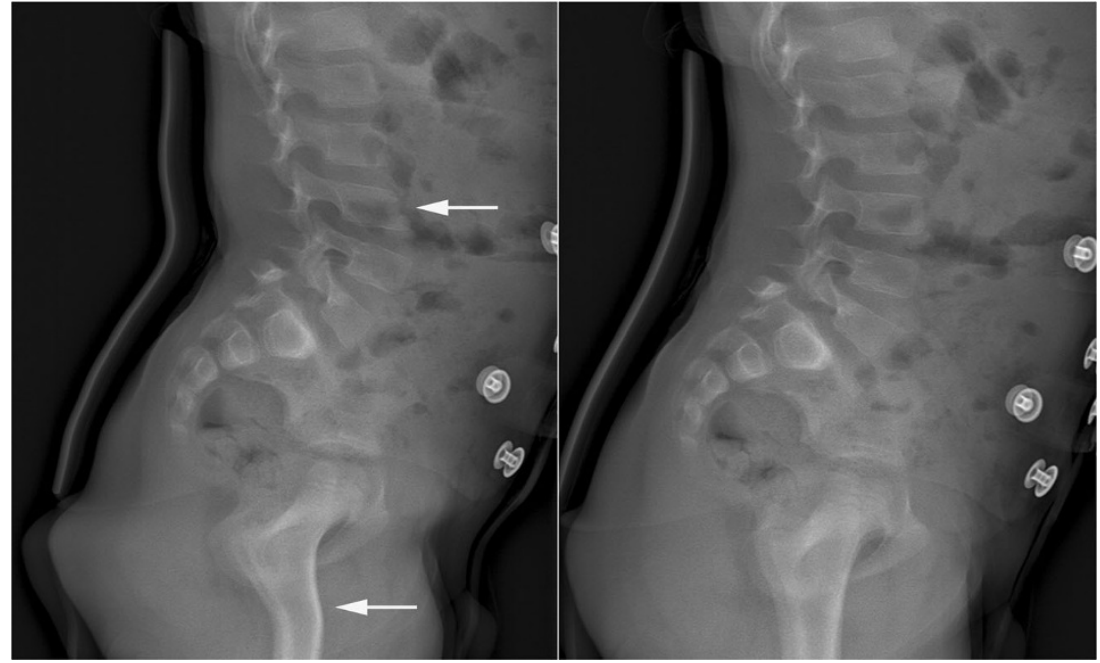

(Biospace Imaging, Paris, France), this digital, biplanar, X-ray imaging acquisition system allows a quick assessment of the entire skeleton in a standing, weight-bearing, position with a significant decrease in radiation dose compared with conventional or other digital radiography systems [7-10]. It also creates $3 \mathrm{D}$ images of the skeleton by using computer models $[6,8,10-15]$. The EOS system is therefore particularly well- suited for diagnosis and monitoring of idiopathic scoliosis in children and adolescents [14, 16, 17], as well as leg-length discrepancy and misalignment [9], and for diagnosis and monitoring of degenerative conditions affecting the spine, hips and knees in adults [18]. This pictorial review aims to familiarise radiologists with the EOS imaging system in evaluation of children and adolescents with idiopathic scoliosis.
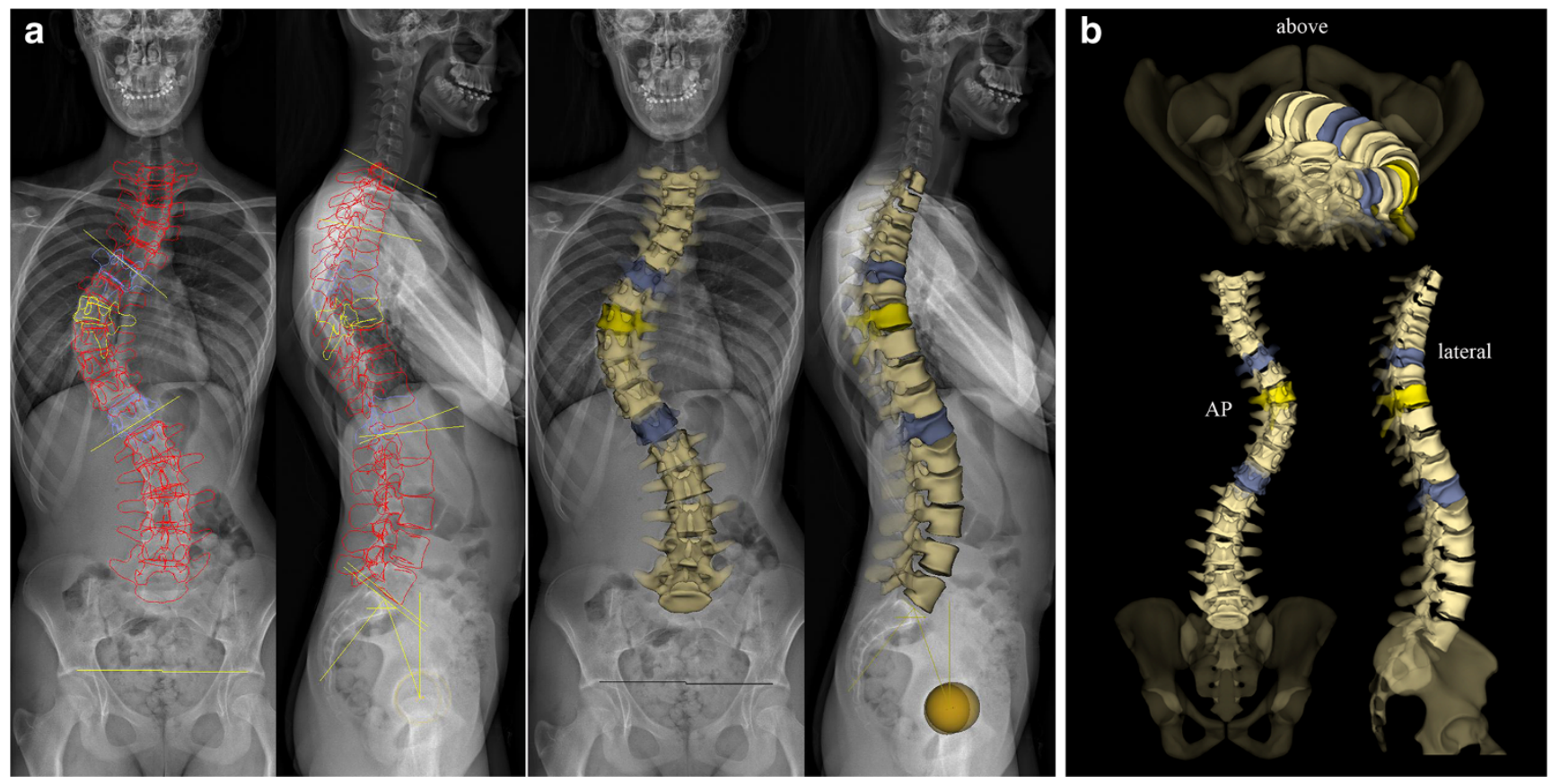

Fig. 4 Surface 3D reconstructions of the spine in a 13-year-old girl with idiopathic thoracic scoliosis. A 3D model of the spine (indicated in red) is generated by the software and overlayed to the native AP and lateral radiographs (a). This model has to be manually adjusted by the operator to precisely match the spinal anatomy. Different perspectives of the spinal deformity are obtained, showing the right thoracic curvature, superior (T6) and inferior (T12) end vertebrae (in blue), and the apical vertebra (T8) in yellow (b). Measurements based on the 3D model are finally automatically computed, including values for spinal curvatures, axial vertebral rotation and pelvic parameters. [Total DAP $\left.=626 \mathrm{mGy} \cdot \mathrm{cm}^{2}\right]$ 


\section{EOS 2D/3D system}

EOS $2 D$ system Using two orthogonal sources of radiation and linear detectors that are coupled together, the EOS system simultaneously produces two orthogonal X-ray images of the skeleton in the weight-bearing position. The child or the adolescent is standing upright (or sitting) in the centre of the device (i.e. at the intersection of the two Xray fan beams) (Fig. 1). Gonadal shielding is usually not applied. Before scanning, the radiology technician defines the limits of the region of interest, in height and width, utilising to two laser beams. The exploration width of the device is limited to $50 \mathrm{~cm}$ (corresponding to a lateral diaphragm being wide open). Vertical scanning from head to pelvis for full spine imaging takes about 5-10 s, whereas scanning from head to toe for full body imaging takes about 15-20 s. Only AP or lateral views may also be acquired. If only frontal radiographs are required, a PA projection is used to lessen the radiation dose to the breasts and gonads. Parameters of acquisition (kilovoltage $[\mathrm{kV}]$ values,
Fig. 6 Surface 3D reconstructions of the spine in a 16-year-old girl with idiopathic thoracolumbar scoliosis before and after surgery. There is a major right thoracic curve (apical vertebral T9) and a minor left lumbar curve before surgery (a). Significant curve correction is seen after surgery (b). Manual adjustment of the 3D model is more difficult after surgery, due to the presence of metal rods, hooks and screws. [Total DAP= $\left.1,868 \mathrm{mGy} \cdot \mathrm{cm}^{2}\right]$

milliampere $[\mathrm{mA}]$ values and scanning speed) are variable, depending on the child's age and weight. The radiology technician can thus choose from three presets: morphotype 1 (slim); 2 (normal) or 3 (corpulent). Acquisition parameters are about $80-90 \mathrm{kV}$ and $200-250 \mathrm{~mA}$ for AP views; $100 \mathrm{kV}$ and $250-320 \mathrm{~mA}$ for lateral views; scanning speed is chosen between 2 and 4 on the vendor-specific scale (ranging from 1 , fast, to 8 , slow). In practice, presets 1 and 2 are used for children (age, 5-12 years; weight about 30-45 kg) and adolescents (age, 13-18 years; weight about $45-70 \mathrm{~kg}$ ) respectively; preset 3 is used only for obese adolescents (weight superior to $75 \mathrm{~kg}$ ). Like for
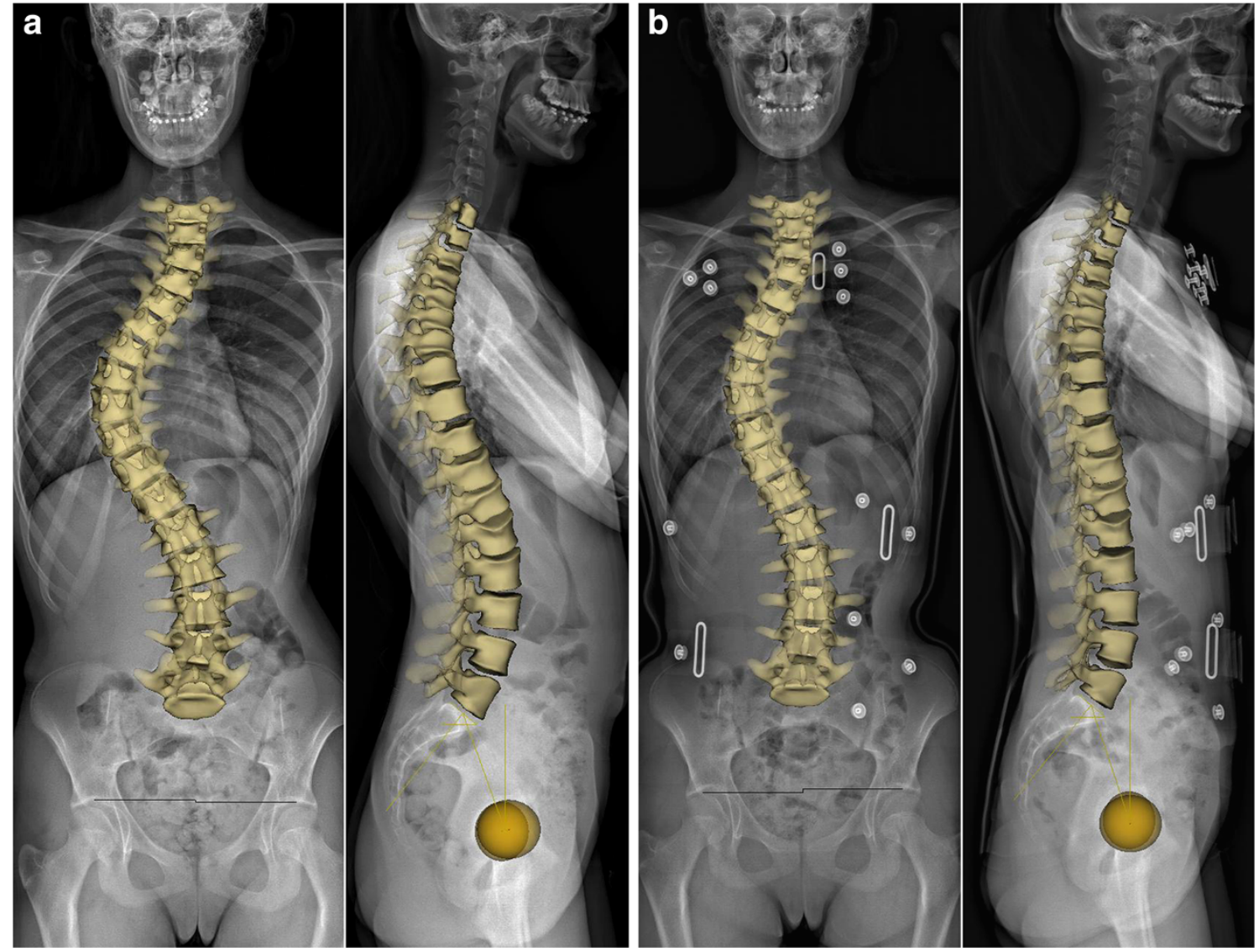

Fig. 5 Surface 3D reconstructions of the spine without and with bracing in a 13-year-old girl. Same patient as in Fig. 4, without (a) and with (b) bracing. [Total DAP without bracing $=626 \mathrm{mGy} \cdot \mathrm{cm}^{2}$; with bracing $=1,263 \mathrm{mGy} \cdot \mathrm{cm}^{2}$ ] 


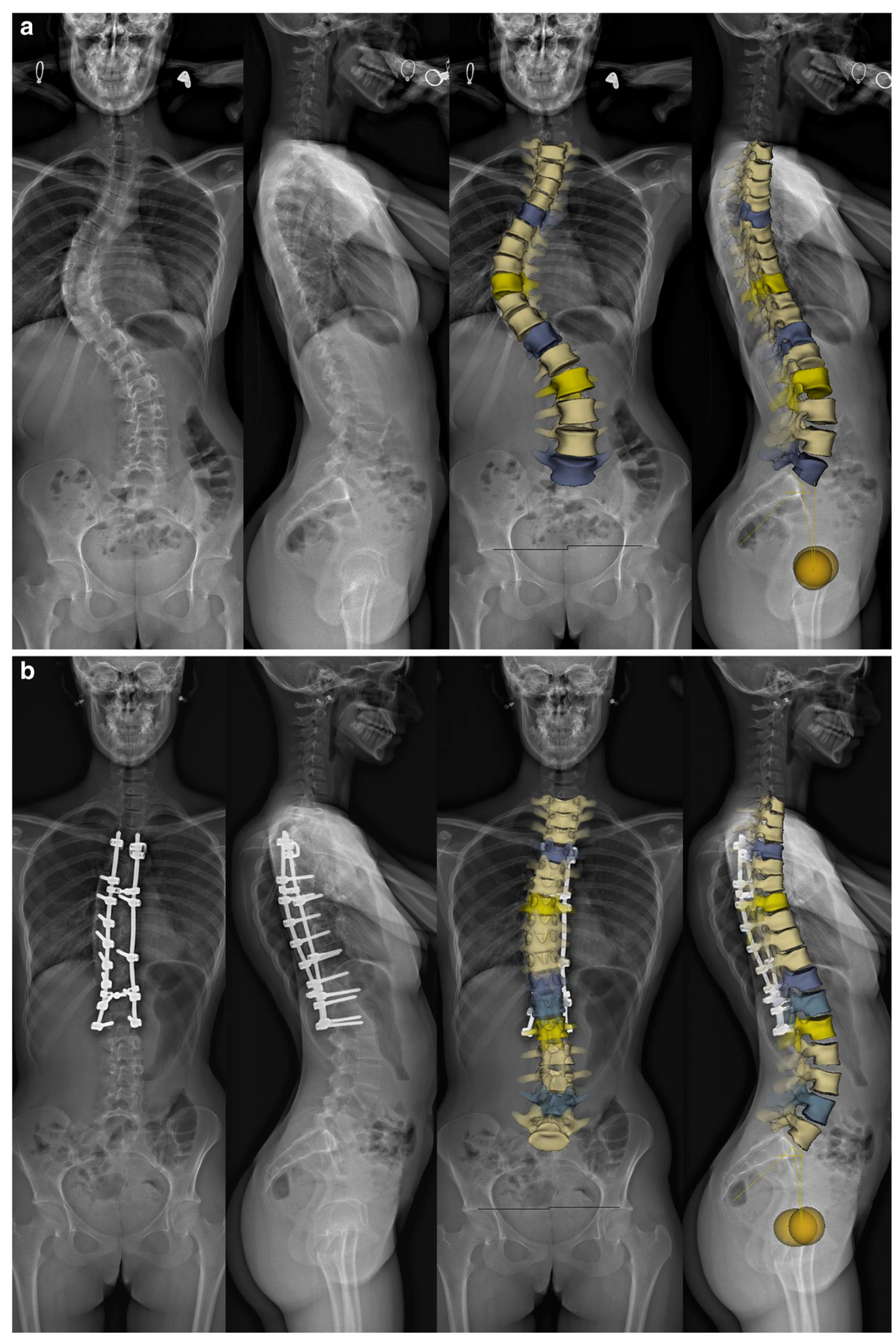


Fig. 7 Major right thoracic and left lumbar idiopathic scoliosis in a 14year-old girl. The severity of the spinal curve on the frontal view and the superimposition of both humeri on the lateral view (a) complicate the visibility of the thoracic vertebrae. In this case, the $3 \mathrm{D}$ reconstruction process can be very time-consuming. Corresponding surface $3 \mathrm{D}$ reconstructions of the spine $(\mathbf{b})$. [Total DAP $=812 \mathrm{mGy} \cdot \mathrm{cm}^{2}$ ]

conventional or other digital radiography systems, child positioning is important to obtain reproducible, comparable radiographs. Among EOS system users, arm positioning is still subject to debate on lateral views because of the superimposition of both humeri on the spine and possible shift in sagittal spinal alignment. The best positioning would be elbows flexed with fists or fingers resting on clavicles or on the cheeks $[19,20]$. In our experience, however, this position is not always easy to maintain; at our hospital, when both AP and lateral views are needed, children and adolescents are positioned with the arms supported in front of them, on a bar or on the device wall.

EOS $3 D$ system Simultaneous production of two orthogonal $\mathrm{X}$-ray images allows the system to generate $3 \mathrm{D}$ images of the skeleton (i.e. the spine, the lower limbs or both) on a dedicated workstation (sterEOS), using key anatomical bony landmarks identified by an operator on the AP and lateral Xray images, a large statistical database, shape recognition techniques and edge-detection algorithms. The mean reconstruction time is about $20-30 \mathrm{~min}$ for $3 \mathrm{D}$ spine rendering, 35-45 min for 3D spine and lower limb rendering. It may be much longer $(>1 \mathrm{~h})$ for patients with severe idiopathic scoliosis.

\section{EOS system versus conventional radiography, other digital radiography systems and computed tomography}

The EOS system differs from conventional radiography, other digital radiography systems and computed tomography (CT) in several regards: firstly, it allows for imaging in a standing position (or a sitting position with disabled children); secondly, it enables whole-body imaging (if necessary); thirdly, it reduces the radiation dose; fourthly, it creates 3D images of the skeleton.

Standing position AP and lateral X-ray images of the spine are acquired in a single vertical scanning mode. Therefore, in contrast to conventional radiography and other digital radiography systems, the EOS system cannot be used in young children with idiopathic infantile scoliosis who cannot stand in the device. In these children, AP and lateral images of the
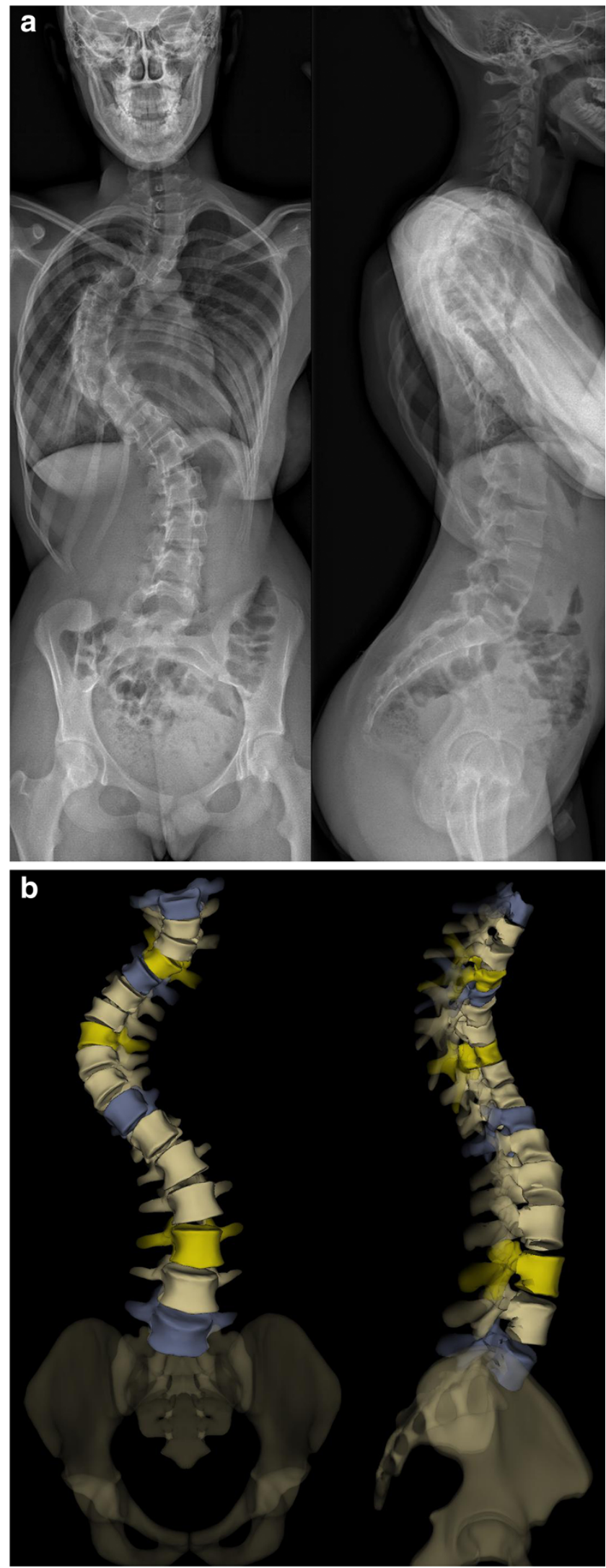
Fig. 8 Idiopathic thoracolumbar scoliosis in a 13-year-old girl presenting with a lumbosacral transitional vertebra. The frontal view (on the left) shows the presence of six lumbar vertebrae. On the corresponding posterior surface $3 \mathrm{D}$ reconstruction of the spine (on the right), the last vertebra seems to be dissociated from the pelvis. This is because the pelvis model does not correspond to a true model of the patient's pelvis. [Total $\mathrm{DAP}=$ $\left.1,040 \mathrm{mGy} \cdot \mathrm{cm}^{2}\right]$

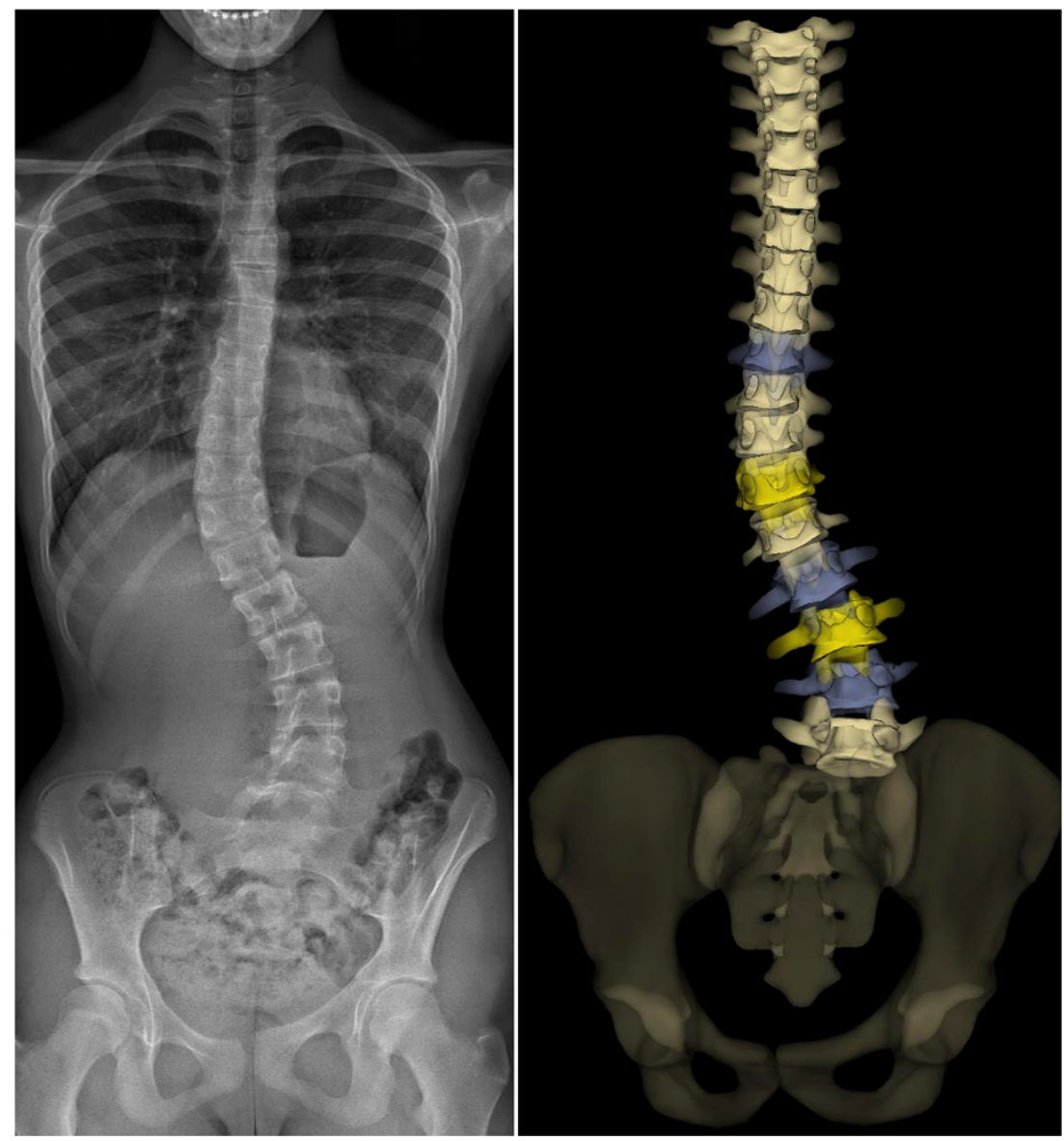

spine have to be performed supine using conventional or, much more frequently, digital radiographic equipment. The latter is now equipped with software that allows automatic stitching of separate cervical, thoracic and lumbar spine

Table 1 Idiopathic scoliosis: spinal and pelvic radiographic parameters

\begin{tabular}{ll}
\hline Coronal Plane & Sagittal Plane \\
\hline Spinal balance & Spinal balance \\
Pelvic obliquity & Spinal parameters \\
& - Thoracic kyphosis \\
& - Lumbar lordosis \\
Scoliosis & Pelvic parameters \\
- Type and side of spinal curve(s) & - Sacral slope \\
- Cobb angle & - Pelvic tilt (or pelvic version) \\
- End vertebrae & - Pelvic incidence \\
Severity of axial rotation & \\
$\quad$ (apical vertebra) & \\
Risser index & \\
\hline
\end{tabular}

radiographs into a single final image. However, some limitations may also be encountered with these techniques (i.e.

Table 2 Lenke classification system

\begin{tabular}{llll}
\hline Curve type & $\begin{array}{l}\text { Lumbar spine } \\
\text { modifier }^{\mathrm{a}}\end{array}$ & $\begin{array}{l}\text { Sagittal thoracic } \\
\text { modifier }^{\mathrm{b}}\end{array}$ \\
\hline $\begin{array}{lll}\text { Type 1 } \\
\text { Type 2 }\end{array}$ & $\begin{array}{l}\text { main thoracic } \\
\text { double thoracic }\end{array}$ & $\mathrm{A}$ & - \\
Type 3 & $\begin{array}{l}\text { double major } \\
\text { triple major }\end{array}$ & $\mathrm{B}$ & $\mathrm{N}$ \\
Type 4 & & + \\
Type 5 & $\begin{array}{l}\text { thoracolumbar/lumbar } \\
\text { thoracolumbar/lumbar } \\
\text { Type } 6\end{array}$ & $\mathrm{C}$ & \\
& $\begin{array}{l}\text { main thoracic } \\
\text { Ty }\end{array}$ & & \\
\hline
\end{tabular}

\footnotetext{
${ }^{a}$ Lumbar spine modifier is assigned on the basis of the relation between the lumbar apical vertebra and the centre sacral vertical line (CSVL): $A$ if the CSVL lies between the pedicles of the apical vertebra; $B$ if the CSVL touches the apical vertebral body and $C$ if the CSVL lies completely medial to the apical vertebral body

${ }^{\mathrm{b}}$ Sagittal thoracic modifier is assigned on the basis of the sagittal alignment from T5 to T12:- if the angle of kyphosis is less than $10^{\circ} ; N$ if the angle of kyphosis is $10-40^{\circ}$; + if the angle of kyphosis is greater than $40^{\circ}$
} 
Fig. 9 Surface 3D reconstructions of the spine in a 12-year-old girl with lumbar idiopathic scoliosis. AP and lateral images (a) and corresponding surface $3 \mathrm{D}$ reconstructions $(\mathbf{b})$ are shown. [Total DAP $=1,027 \mathrm{mGy} \cdot \mathrm{cm}^{2}$ ]

geometric distortion and stitching errors in conventional and digital imaging respectively) [21].

Whole-body imaging The EOS system can acquire X-ray images of the entire skeleton. This may be very useful for assessing relationships between the spine, the pelvis and the lower extremities in standing functional position (Fig. 2). In fact, significant leg length discrepancy may be responsible for pelvic obliquity and lumbar scoliosis [22]. However, scanning from the base of the skull to the toes requires longer acquisition times; specific artefacts due to patient's movement therefore may occur in children unable to stay still while performing scanning, resulting in distorted images (Fig. 3).

Dose reduction The EOS system allows a significant reduction of radiation dose, by a factor of 2.5-10 compared with 2D conventional radiography and other digital radiography systems $[6,7,9,10,23]$ and by a factor of up to $800-1,000$ compared with $3 \mathrm{D} \mathrm{CT}$ reconstructions [6]. In our experience, we found a dose reduced by a factor of 4 when comparing our EOS system (average dose area product or DAP of $23.6 \mathrm{mGy} \cdot \mathrm{cm}^{2} / \mathrm{kg} \pm 4.32$ ) with our digital radiography system (average DAP of $95.7 \mathrm{mGy} \cdot \mathrm{cm}^{2} / \mathrm{kg} \pm 30.39$ ) in children with idiopathic scoliosis requiring both AP and lateral views.

With the EOS system, the dose depends on $\mathrm{kV}$ and $\mathrm{mA}$ values, the chosen preset (1, 2 or 3$)$, the scanning speed and the region of interest. For simultaneous AP and lateral radiographs of the spine, the total DAP is around $860 \mathrm{mGy} \cdot \mathrm{cm}^{2}$ for morphotype 1 (child), around $1,180 \mathrm{mGy} \cdot \mathrm{cm}^{2}$ for morphotype 2 (adolescent) and around 1,780 $\mathrm{mGy} \cdot \mathrm{cm}^{2}$ for morphotype 3 (obese adolescent). The radiation dose decreases when the translational speed of the X-ray tubes increases (but the image quality decreases as well). It also decreases when the fan-shaped beam of photons is laterally collimated.

Three-dimensional images of the skeleton Idiopathic scoliosis is characterised by a vertebral deviation in the coronal and sagittal planes but also by a vertebral rotation in the axial (or horizontal) plane. Axial vertebral rotation is difficult to assess on 2D radiographs but it may be explored with CT scans and 3D CT reconstructions [24, 25]. This technique is, however, performed in the supine position; it is limited to short spinal segments and requires a higher radiation dose than conventional or digital radiography, even at low CT doses. In contrast, the EOS system provides large size 3D
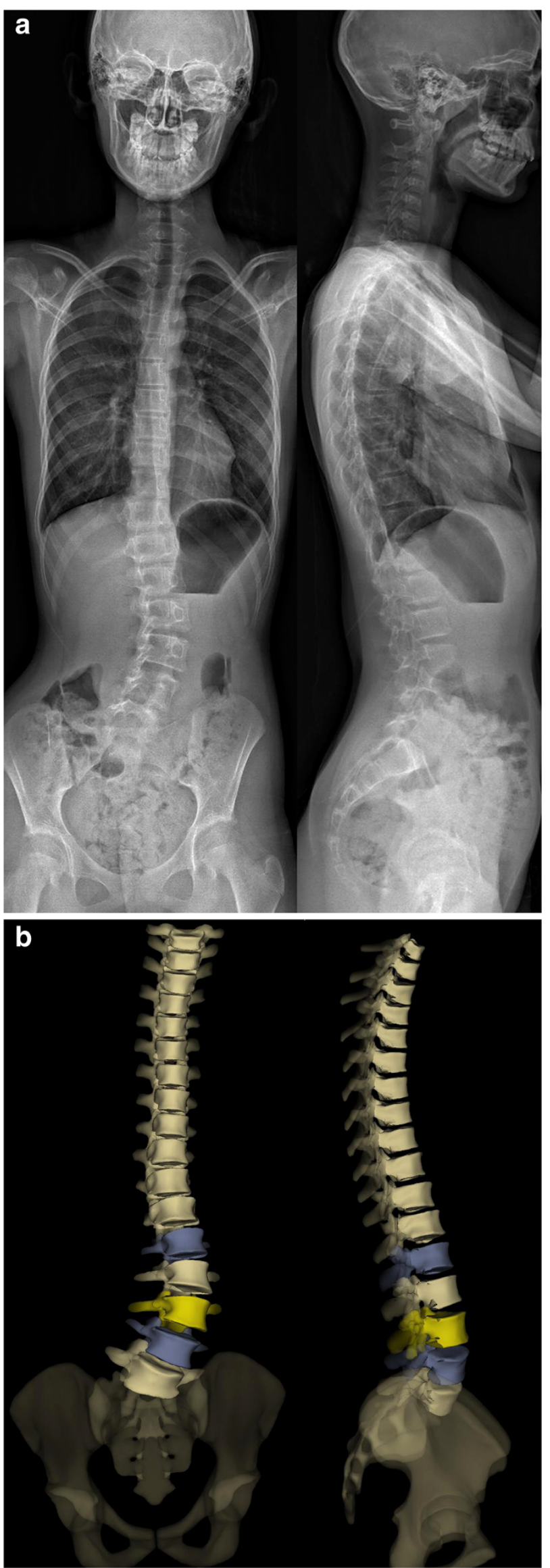
Fig. 10 Surface 3D reconstructions of the spine in a 13-year-old girl with double thoracic idiopathic scoliosis. AP and lateral images (a) and corresponding surface 3D reconstructions (b) are shown. [Total DAP: $\left.1,029 \mathrm{mGy} \cdot \mathrm{cm}^{2}\right]$

images of the spine (Fig. 4) from the two lowered-dose Xrays, with no additional radiation and in standing functional position. Three-dimensional EOS images differ from CT reconstructions in that they correspond to surface reconstructions (that are not validated yet in congenital scoliosis) and not real reconstructions. These $3 \mathrm{D}$ images provide a better understanding of the spinal deformity from different perspectives (Fig. 4). They may be performed with and without bracing (Fig. 5) or before and after surgery (Fig. 6). Once $3 \mathrm{D}$ images are complete, the software automatically generates measurements related to spinal coronal (Cobb angle) and sagittal curves (thoracic kyphosis, lumbar lordosis), and to pelvic parameters. Since they have been computed from 3D space, these measurements have been shown to be more accurate, reliable and reproducible $[15,26]$. In current practice, however, some difficulties may be encountered during the $3 \mathrm{D}$ reconstruction process. A severe curvature in the coronal plane is responsible for poor visibility of some vertebrae in the sagittal plane, making the adjustment of the model by the operator more difficult (Fig. 7). The presence of lumbosacral transitional vertebrae (i.e. sacralisation of L5 or lumbarisation of S1) is another cause of difficulty since the sterEOS 3D software is not validated yet for this type of anatomical variant (Fig. 8). In this case, the best solution for the operator is to exclude the transitional vertebra from the $3 \mathrm{D}$ reconstruction process.

\section{EOS 2D/3D system in the assessment of idiopathic scoliosis}

EOS $2 D$ system It can be used to determine the usual spinal and pelvic radiographic parameters in both the coronal and sagittal planes (Table 1), and to assess skeletal maturity [27-34]. According to the Lenke classification system (Table 2), different types of scoliosis may be encountered (Figs. 4, 6, 7, 9 and 10). This classification takes into account the curve type in the coronal plane (structural curve versus non-structural curve[s]), its location (thoracic, lumbar or thoraco-lumbar), its flexibility, and the curves in the sagittal plane to guide surgical treatment of scoliosis [35]. Therefore, it requires standing frontal and lateral spinal radiographs as well as rightward- and leftward-bending radiographs. The latter are useful to make the distinction between the structural curve (also called the primary or the major curve) and the non-structural curves (also called secondary curves or minor curves) before surgery. The
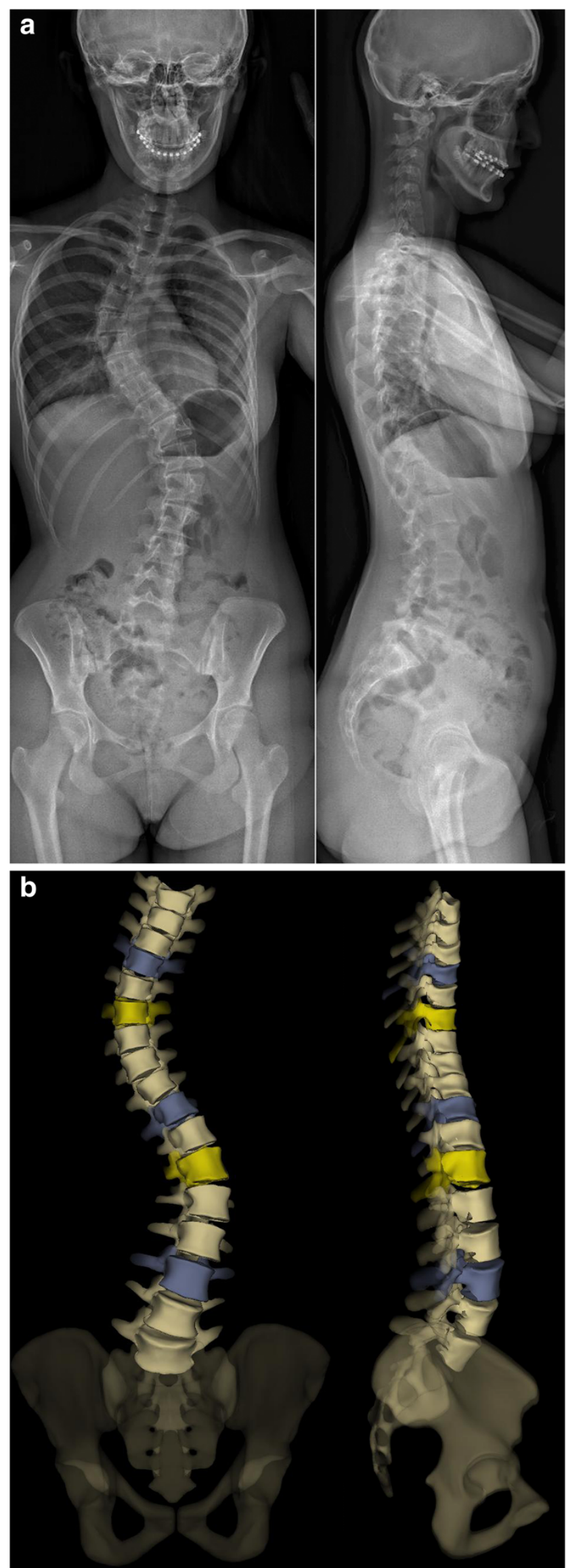
structural curve is the largest curve, the one exhibiting more vertebral rotation and the least flexible one (i.e. the one that is non-correctable or partially correctable on ipsilateral sideward-bending with a Cobb angle $\geq 25^{\circ}$ ) [35]. It is usually included in operative fusion. In contrast, the non-structural curves are the smallest curves, those exhibiting less vertebral rotation and the most flexible ones (i.e. the ones that are non-correctable or partially correctable on ipsilateral sideward-bending views with a Cobb angle $<25^{\circ}$ ) [1].They develop secondarily, and are usually not included in operative fusion. Rightward- and leftward-bending radiographs are not currently validated in the EOS device, but they may be performed in positioning the patient off-centre within the system (Fig. 11).

EOS $3 D$ system It can be used to measure the degree of axial vertebral rotation. This is usually assessed semiquantitatively on frontal radiographs by different methods, in which the spinous process location (Cobb) [36] or the pedicle location [37-39] are used as indirect indicators of the severity of axial vertebral rotation. In our institution, we prefer the Nash-Moe method (Fig. 12) or each time if possible, the direct assessment of axial vertebral rotation with the EOS system and its top view method (Fig. 13).

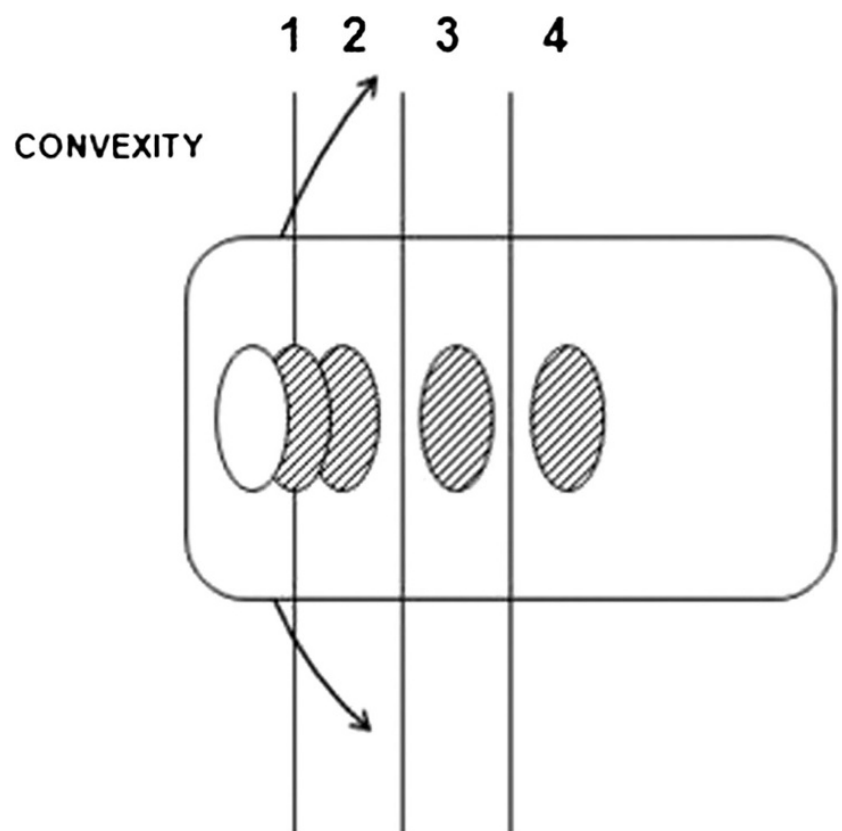

Fig. 12 Axial vertebral rotation assessed by the Nash-Moe method. This 2D method uses the position of pedicles as reference landmarks. The half vertebra on the side of convexity is divided into three segments. If there is no axial vertebral rotation (grade 0), the pedicle is seen within the outer segment. As the degree of axial vertebral rotation increases (grades 1-4), the convex-side pedicle migrates towards the side of concavity
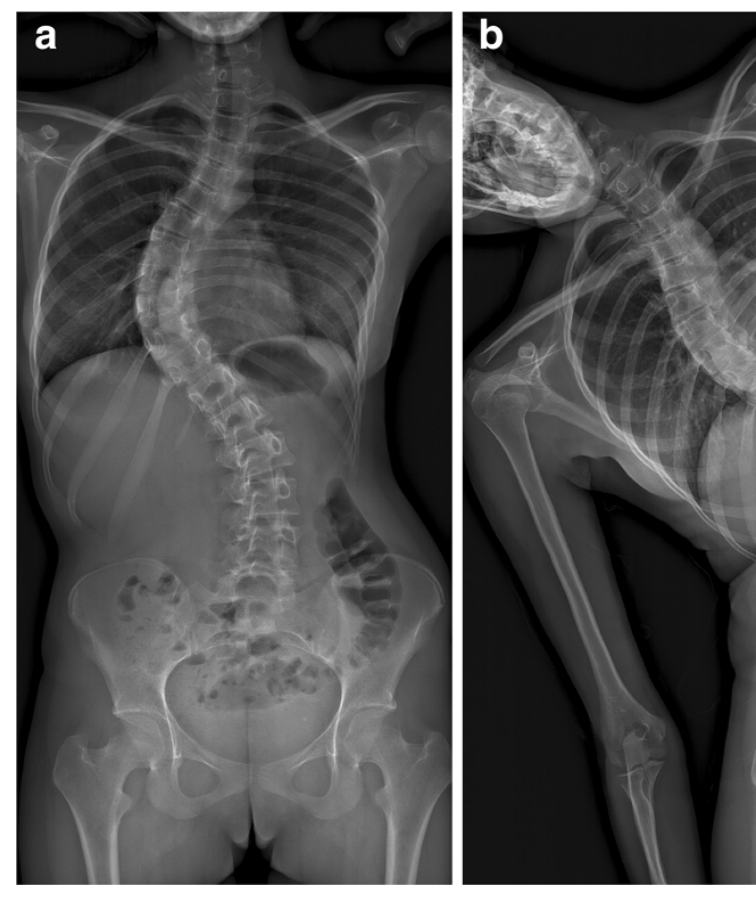

Fig. 11 Structural versus non-structural spinal curves in a 15-year-old girl. The AP radiograph reveals right thoracic and left lumbar curvatures (a). On bending radiographs (b), the right thoracic curve (structural curve) is non-correctable, whereas the left lumbar curve (non-structural curve) is correctable with bending to the left. [Total DAP $=864 \mathrm{mGy} \cdot \mathrm{cm}^{2}$ ] 
Fig. 13 Axial vertebral rotation assessed by the EOS method.

This 3D method shows position and rotation of the apical vertebra (in yellow) on a top view (a). With this method, each vertebra is represented by a vector, which is placed in a coordinate system $(x, y$ and $z$ where $x$ corresponds to the interacetabular axis). This

vertebral vector gives information about position and rotation of the vertebra in horizontal plane (note: the scale is based on the interacetabular distance). Apical (yellow) and end (dark blue) vertebrae are indicated (a). Another way of showing position and rotation of apical (T8) and end (T6, T12) vertebrae in horizontal plane is given by a diagram (b)
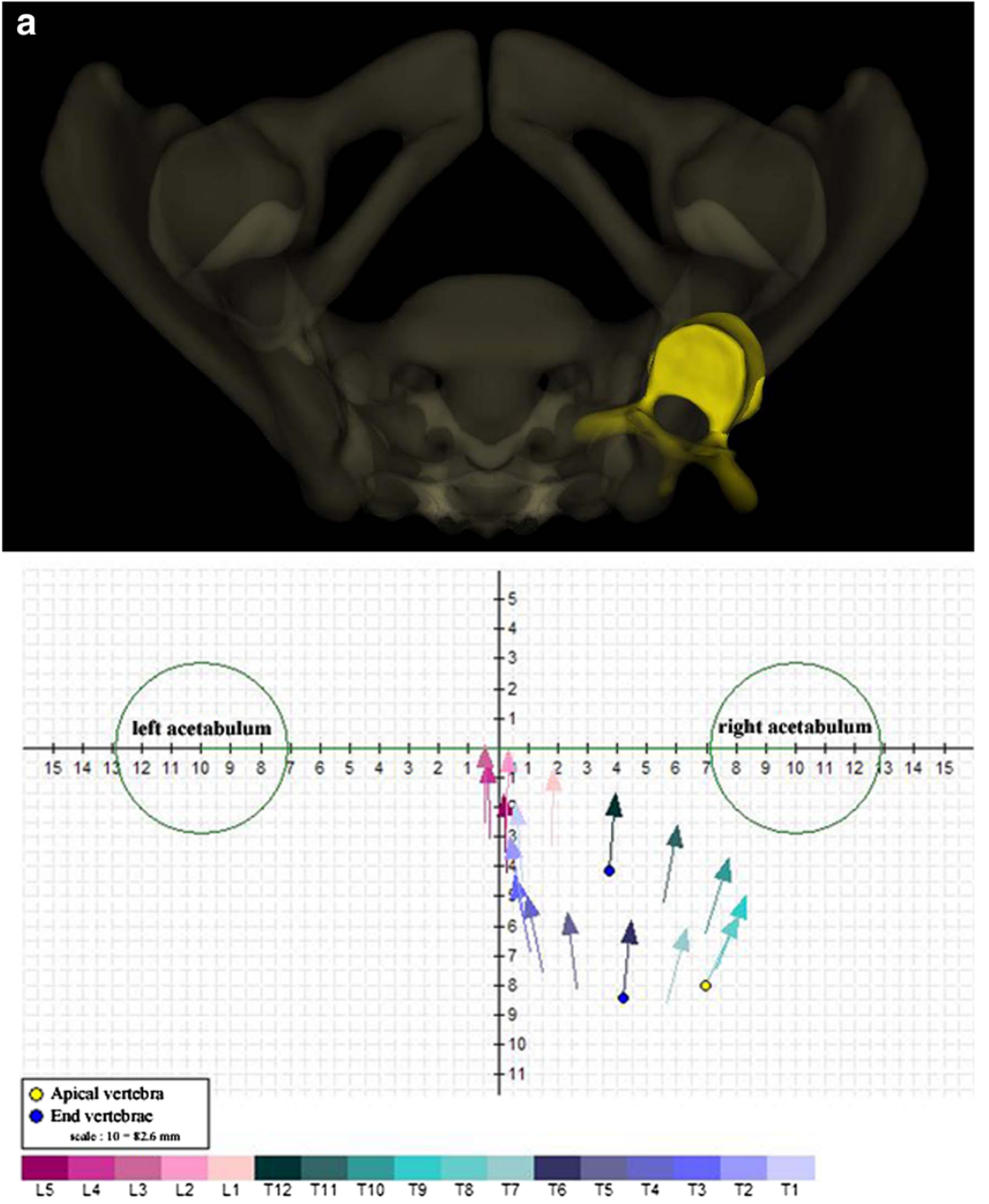

b

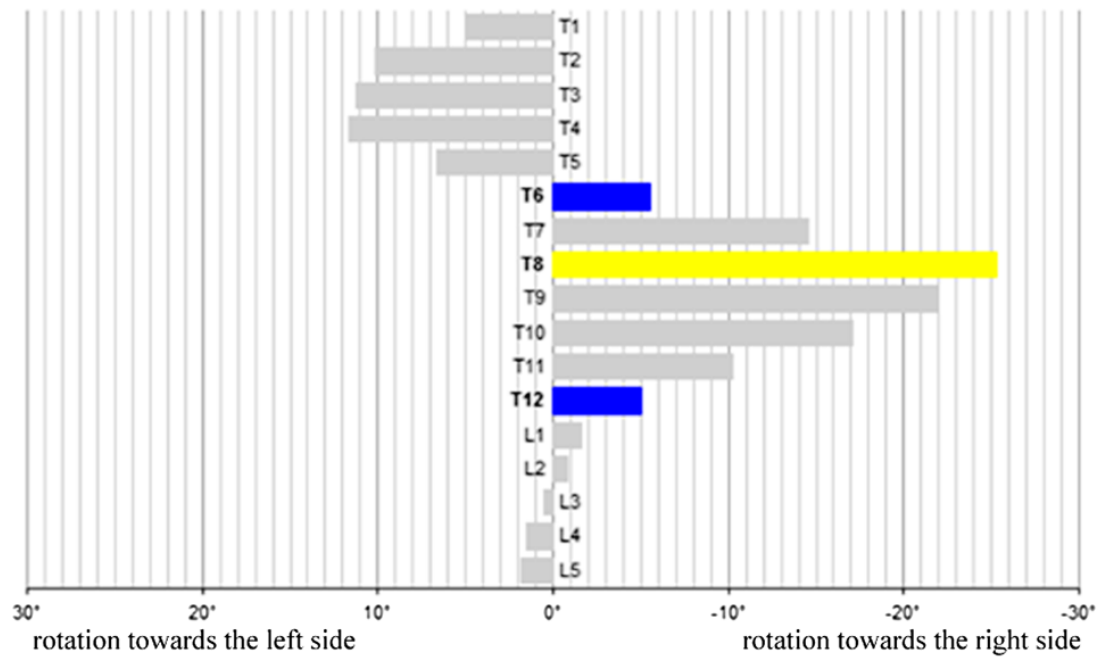

Apical vertebra

End vertebrae 

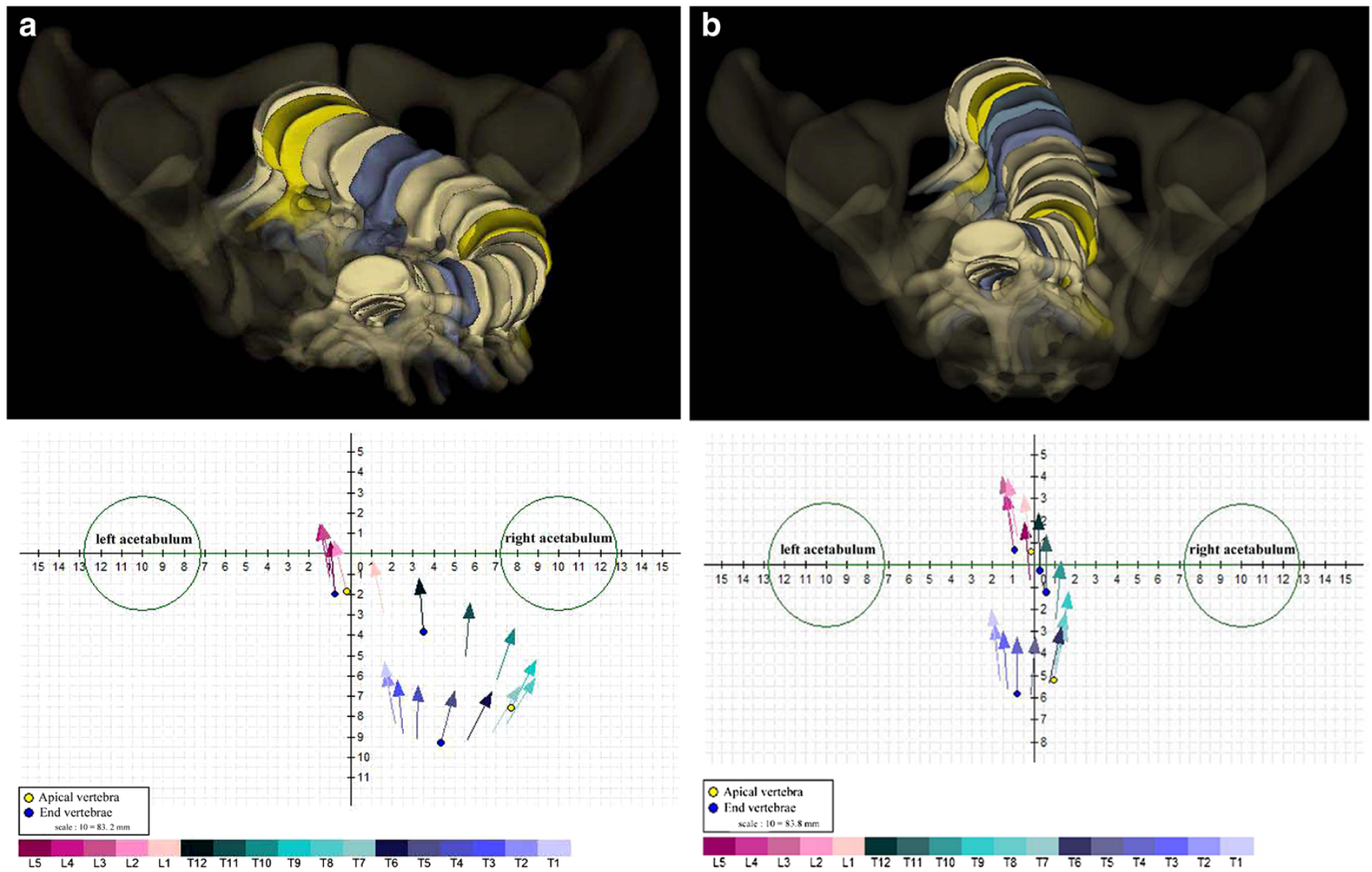

Fig. 14 Axial vertebral rotation assessed by the EOS method before and after surgery. Corresponding top view 3D reconstructions and vertebral vectors, before (a) and after (b) surgery in the same patient as in Fig. 6

This method shows the position and rotation of the apical vertebra in the horizontal plane based on the interacetabular distance (Fig. 13). More recently, via the concept of "vertebral vectors", Illés et al. [17, 40] found another way to visualise the position of all vertebrae, including the apical one, in the horizontal plane and, most importantly, to quantify the vertebral rotation in all three planes simultaneously (Fig. 13). This may be used to show the evolution of scoliosis before and after surgery (Fig. 14).

In conclusion, radiography plays a pivotal role in the evaluation of children and adolescents with idiopathic scoliosis. However, it is limited to 2D measurements of frontal and sagittal spinal curves, and regular follow-up until skeletal maturity requires repeated $\mathrm{X}$-ray exposure. The EOS $2 \mathrm{D} / 3 \mathrm{D}$ system is a biplanar X-ray system that appeared in 2005 to overcome these drawbacks. It allows imaging of the spine at lowered radiation levels. Another advantage is the possibility of obtaining $3 \mathrm{D}$ images of the spine in the standing functional position. This new imaging technique is therefore increasingly being used in paediatric imaging departments. In the present article we have provided an overview of the potential usefulness of the EOS 2D/3D system in children and adolescents with idiopathic scoliosis; however, it appears too early to assess precisely its $3 \mathrm{D}$ ability and its impact on therapeutic management.

Acknowledgments The authors would like to thank Aymeric FREMEAUX for the surface $3 \mathrm{D}$ reconstructions of the spine.

Open Access This article is distributed under the terms of the Creative Commons Attribution License which permits any use, distribution, and reproduction in any medium, provided the original author(s) and the source are credited.

\section{References}

1. Kim H, Kim HS, Moon ES, Yoon CS, Chung TS, Song HT et al (2010) Scoliosis imaging: what radiologists should know. Radiographics 30:1823-1842

2. Nash CL Jr, Gregg EC, Brown RH, Pillai K (1979) Risks of exposure to X-rays in patients undergoing long-term treatment for scoliosis. $\mathrm{J}$ Bone Joint Surg Am 61:371-374

3. Hoffman DA, Lonstein JE, Morin MM, Visscher W, Harris BS 3rd, Boice JD Jr (1989) Breast cancer in women with scoliosis exposed to multiple diagnostic x rays. J Natl Cancer Inst 81:1307-1312 
4. Ronckers CM, Land CE, Miller JS, Stovall M, Lonstein JE, Doody MM (2010) Cancer mortality among women frequently exposed to radiographic examinations for spinal disorders. Radiat Res 174:8390

5. Goldberg MS, Mayo NE, Levy AR, Scott SC, Poîtras B (1998) Adverse reproductive outcomes among women exposed to low levels of ionizing radiation from diagnostic radiography for adolescent idiopathic scoliosis. Epidemiology 9:271-278

6. Dubousset J, Charpak G, Dorion I, Skalli W, Lavaste F, Deguise J et al (2005) A new 2D and 3D imaging approach to musculoskeletal physiology and pathology with low-dose radiation and the standing position: the EOS system. Bull Acad Natl Med 189:287-297

7. Deschênes S, Charron G, Beaudoin G, Labelle H, Dubois J, Miron MC et al (2010) Diagnostic imaging of spinal deformities: reducing patients radiation dose with a new slot-scanning X-ray imager. Spine 35:989-994

8. McKenna C, Wade R, Faria R, Yang H, Stirk L, Gummerson N et al (2012) EOS 2D/3D X-ray imaging system: a systematic review and economic evaluation. Health Technol Assess 16:1-188

9. Gheno R, Nectoux E, Herbaux B, Baldisserotto M, Glock L, Cotten A et al (2012) Three-dimensional measurements of the lower extremity in children and adolescents using a LDBX-ray device. Eur Radiol 22:765-771

10. Dubousset J, Charpak G, Skalli W, Kalifa G, Lazennec JY (2007) EOS stereo-radiography system: whole-body simultaneous anteroposterior and lateral radiographs with very low radiation dose. Rev Chir Orthop Reparatrice Appar Mot 93:141-143

11. Aubin CE, Dansereau J, Parent F, Labelle H, de Guise JA (1997) Morphometric evaluations of personalised 3D reconstructions and geometric models of the human spine. Med Biol Eng Comput 35:611-618

12. Dumas R, Aissaoui R, Mitton D, Skalli W, de Guise JA (2005) Personalized body segment parameters from biplanar low-dose radiography. IEEE Trans Biomed Eng 52:1756-1763

13. Baudoin A, Skalli W, de Guise JA, Mitton D (2008) Parametric subject-specific model for in vivo $3 \mathrm{D}$ reconstruction using bi-planar X-rays: application to the upper femoral extremity. Med Biol Eng Comput 46:799-805

14. Humbert L, De Guise JA, Aubert B, Godbout B, Skalli W (2009) 3D reconstruction of the spine from biplanar X-rays using parametric models based on transversal and longitudinal inferences. Med Eng Phys 31:681-687

15. Glaser DA, Doan J, Newton PO (2012) Comparison of 3D spinal reconstruction accuracy: biplanar radiographs with EOS versus computed tomography. Spine 37:1391-1397

16. Ilharreborde B, Steffen JS, Nectoux E, Vital JM, Mazda K, Skalli W et al (2011) Angle measurement reproducibility using EOS threedimensional reconstructions in adolescent idiopathic scoliosis treated by posterior instrumentation. Spine 36:1306-1313

17. Illés T, Tunyogi-Csapó M, Somoskeöy S (2011) Breakthrough in three-dimensional scoliosis diagnosis: significance of horizontal plane view and vertebra vectors. Eur Spine J 20:135-143

18. Than P, Szuper K, Somoskeöy S, Warta V, Illlés T (2012) Geometrical values of the normal and arthritic hip and knee detected with the EOS imaging system. Int Orthop 36:1291-1297

19. Faro FD, Marks MC, Pawelek J, Newton PO (2004) Evaluation of a functional position for lateral radiograph acquisition in adolescent idiopathic scoliosis. Spine 29:2284-2289

20. Morvan G, Mathieu P, Vuillemin V, Guerini H, Bossard P, Zeitoun F et al (2011) Standardized way for imaging of the sagittal spinal balance. Eur Spine J 20(Suppl 5):602

21. Supakul N, Newbrough K, Cohen MD, Jennings SG (2012) Diagnostic errors from digital stitching of scoliosis images - the importance of evaluating the source images prior to making a final diagnosis. Pediatr Radiol 42:584-598

22. Raczkowski JW, Daniszewska B, Zolynski K (2010) Functional scoliosis caused by leg length discrepancy. Arch Med Sci 6:393-398

23. Dietrich TJ, Pfirrmann CW, Schwab A, Pankalla K, Buck FM (2013) Comparison of radiation dose, workflow, patient comfort and financial break-even of standard digital radiography and a novel biplanar low-dose X-ray system for upright full-length lower limb and whole spine radiography. Skelet Radiol 42:959-967

24. Aaro S, Dahlborn M (1981) Estimation of vertebral rotation and the spinal and rib cage deformity in scoliosis by computer tomography. Spine 6:460-467

25. Ho EK, Upadhyay SS, Ferris L, Chan FL, Bacon-Shone J, Hsu LC et al (1992) A comparative study of computed tomographic and plain radiographic methods to measure vertebral rotation in adolescent idiopathic scoliosis. Spine 17:771-774

26. Somoskeöy S, Tunyogi-Csapo M, Bogyo C, Illés T (2012) Accuracy and reliability of coronal and sagittal spinal curvature data based on patient-specific three-dimensional models created by the EOS 2D/3D imaging system. Spine J 12:1052-1059

27. Mac-Thiong JM, Labelle H, Berthonnaud E, Betz RR, Roussouly P (2007) Sagittal spinopelvic balance in normal children and adolescents. Eur Spine J 16:227-234

28. Vidal C, Ilharreborde B, Azoulay R, Sebag G, Mazda K (2013) Reliability of cervical lordosis and global sagittal spinal balance measurements in adolescent idiopathic scoliosis. Eur Spine J 22: 1362-1367

29. Roussouly P, Nnadi C (2010) Sagittal plane deformity: an overview of interpretation and management. Eur Spine J 19:1824-1836

30. Legaye J, Duval-Beaupère G, Hecquet J, Marty C (1998) Pelvic incidence: a fundamental pelvic parameter for three-dimensional regulation of spinal sagittal curves. Eur Spine J 7:99-103

31. Legaye J (2007) The femoro-sacral posterior angle: an anatomical sagittal pelvic parameter usable with dome-shaped sacrum. Eur Spine J 16:219-225

32. Stagnara P, De Mauroy JC, Dran G, Gonon GP, Costanzo G, Dimnet $\mathrm{J}$ et al (1982) Reciprocal angulation of vertebral bodies in a sagittal plane: approach to references for the evaluation of kyphosis and lordosis. Spine 7:335-342

33. Roussouly P, Berthonnaud E, Dimnet J (2003) Geometrical and mechanical analysis of lumbar lordosis in an asymptomatic population: proposed classification. Rev Chir Orthop Reparatrice Appar Mot 89:632-639

34. Tan KJ, Moe MM, Vaithinathan R, Wong HK (2009) Curve progression in idiopathic scoliosis: follow-up study to skeletal maturity. Spine 34:697-700

35. Lenke LG, Betz RR, Harms J, Bridwell KH, Clements DH, Lowe TG et al (2001) Adolescent idiopathic scoliosis: a new classification to determine extent of spinal arthrodesis. J Bone Joint Surg Am 83: $1169-1181$

36. Cobb JR (1948) Outline for the study of scoliosis. Instructional Course Lectures. Am Acad Orthop Surg 5:261-275

37. Perdriolle R, Vidal J (1985) Thoracic idiopathic scoliosis curve evaluation and prognosis. Spine 20:546-553

38. Nash C, Moe JH (1969) A study of vertebral rotation. J Bone Joint Surg 51:223-229

39. Drerup B (1984) Principles of measurement of vertebral rotation from frontal projection of the pedicles. J Biomech 17:923-935

40. Illés T, Somoskeöy S (2013) Comparison of scoliosis measurements based on three-dimensional vertebra vectors and conventional twodimensional measurements: advantages in evaluation of prognosis and surgical results. Eur Spine J 22:1255-1263 